\title{
La Peli-Muerfada
}

\section{(Epopeya de filtima moda)}

\author{
CANTO PRIMERO * \\ Cantó Ercilla al araucano, \\ Tasso cantó a Godofredo. \\ cantó a Bolívar Olmedo \\ y a César cantó lucano; \\ vate del codo a la mano, \\ como me suelen llamar. \\ yo tombién voy a cantar \\ mas que alborote el cotarro. \\ $y$ aunque estoy con un catarro \\ que no puedo resollor. \\ Si epopeyas hacen cien. \\ aúm los quec vanea la escuelaso" \\ sobre el muerto $y$ quien lo vela \\ he de hacerlas yo también. \\ Con un trés bon o un trés bien
}

(*) Aparece como "introducción" del poema, en la recopilación póstuma de los Artículos, poesias y comedias de Manuel Ascencio Segura. $\mathrm{Y}$ así lo ha transcrito Ventura García Calderón en Parnaso Peruano (Barcelona, Casa Editorial Maucci, s. a.), pp. 22-24: y en Costumbristas y Satíricos (Paris, Biblioteca de Cultura Peruana, 1938), pp. 216-218. que".

8.- Mas que, barbarismo de uso muy extendido, en lugar de "aun-

15.- No sólo hace burla de los apasionados admiradores de la literatura francesa, al mencionar las locuciones trés bon y trés bien. Quizá deba entenderse que la sátira se halla especialmente enderezada contra la cursi afectación de quienes intercalaban expresiones francesas en su conversación, y muchas veces sin entenderlas ni saberlas pronunciar : porque las exigencias de la rima obligan a deformar la pronunciación de trés bien. 
no es Beranger quien me ofusca;

$y$, aunque la gente pardusca

después me devane el seso,

he de soltar la sin hueso

más recio que la Cuyusca.

Pelanduscas del Parnaso, ivenid todas en mi ayuda! Con la primera que acuda aun sin cunquibus me caso. Mas, si a mi numen escaso lo dejáis en abandono, juro que ha de ser mi encono tan grande contra vosotras, que me han de salir tres potras subiendo a soprano el tono.

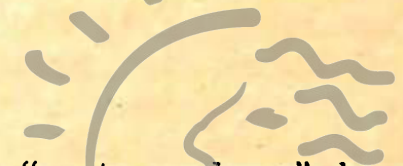

17.- La alusión a la "gente pardusca", ha sido interpretada como expresión de cierto antagonismo entre Manuel Ascencio Segura y Felipe Pardo, especialmente por Luis Alberto Sánchez y su discípulo M. Maurilio Arriola Grande. En verdad, refleja sólo el circunstancial desdén que el autor consagra a la gente de color pardo, para zaherir así al inspirador de La Peli-Muertada. $Y$ se hará evidente que este poema no alude a Felipe Pardo si se tiene presente por qué se aplicó a su protagonista el apelativo de Peli-Muerto, según se refiere en, los versos 11321151: "es que se puso al capricho / lacia y rubia una peluca, / para taparla a su nuca / lo de lo negro bozal. / Y que luego en la Comedia / se presentó así contrahecho, / en palco y muy satisfecho, / el hijo del capataz; / y que al menos hora y media / durarían las palmadas, / los silbos y carcajadas / que allí causó este disfraz".....

20.- Cuyusca, mujerzuela de Piura. (N. del A.). Una maliciosa evocación de la Cuyusca ha sido incluícla por Enrique López Albújar en sus "poemas afroyungas" De la tierra brava (Lima, 1938). De ella se deduce que la aludida "mujerzuela" era una negra sensual, que vendía viandas populares y en sus pregones endilgaba interjecciones y voces groseras.

24.- Cunquibus, equivale a "con qué". En este caso no importa que el latinismo esté bien o mal usado, que corresponda a la expresión o implique una incoherencia. Se trata de imitar el habla de la gente "de medio pelo", que rezumaba más presunción que cultura. Y, por la misma razón, Manuel Ascensio Segura emplea más adelante las locuciones : non sancta, per omnia soecula, ipso facto, quis vel quid, non plus y necuacuam. 
Que este sea o no poema

a mí me importa tres rábanos,

ni que me piquen los tábanos

hasta hacerme una apostema.

Que lo lean es mi tema,

sin engañifa ni trampa,

el que maneja una lampa,

el que varea tocuyo,

el que vive allá por Suyo

40

y el que duerme acá en la pampa.

Ya el estro me va inflamando:

echadme una pipa de agua...

Siento el pecho como fragua...

45

¡Por Dios, que me estoy quemandol

Ya el preludio va cansando,

y si un poco más me embromo

me derrito como plomo

- me transformo en carbón...

50

Silencio, pues, y jatenciónl

que voy a hablar como un tomo.

\section{CANTO SEGUNDO *}

En el Callao joh fortunal

al pie de una santa cruz

vió Peli-muerto la luz

en una noche de luna.

Uno que andaba de tuna

31-40.- Burla burlando, Manuel Ascencio Segura expone en está décima la orientación popular de su inspiración y su estilo : pues, a despecho de las convenciones retóricas y las exigencias formales de la crítica, sólo pretende que lo entienda aún el jornalero de las agros costeños. "Hablen los mismos idiomas los hombres y las nayades", dirá más adelante, para anunciar que unas veces respeta el equilibrio clásico, y otras se acoge a la libertad felizmente instaurada por el romanticismo. (Cf. versos 163-202).

39.- Suyo, pueblo de Piura. (N. del A.). Es capital del distrito de su nombre, perteneciente a la provincia de Ayabaca.

(*) Aparece como "canto primero" del poema en la recopilación póstuma de los Artículos, poesías y comedias de Manuel Ascencio Segura; pero en la trascripción ha quedado suprimida la quinta décima (versos 91-100). $\mathrm{Y}$ con denominación y omisión iguales lo inserta Ventura García Calderón en Parnaso Peruano (Barcelona, Casa Editorial Maucci, s. a.), pp. 24-26; y en Costumbristas y Satíricos (París, Biblioteca de Cultura Peruana, 1938), pp. 218-220. 
por el tal sitio a esas horas lo envolvió en unas totoras de un capacho destrozado que allí cerca habían botado unas indias pescadoras.

- Por mi padre San Antonio!

-al verlo exclamó el borracho-que promete este muchacho ser malo como un demonio. Para alzar un testimonio no habrá ninguno como él, ni para armar un pastel otro en el mundo más ducho. Con el tiempo este avechucho ha de hacer un gran papel.

Dijo, y ladeándose el pelo que le caía adelante, tomó de prisa el portante dejando al chico en el suelo. En este instante el monuelo como un chivato gritaba; el reloj las doce daba, olía el aire a champús, y $\sin$ decir chus ni mus la parturienta aguantaba.

\section{Vino eb día, y la gentusanverso"} que anda de lances en pista, en corro pasó revista del chico hasta la pelusa. - iAjol Botarlo a la inclusa - exclamó un gallego viejo. -No señor, por mi consejo,

78.- "Sin razón ninguna especial", Juan de Arona escribe champuz y no champús. Sugiere que "tal vez le venía el nombre de su forma de champa" (quechuísmo que, por extensión, denomina a "cualquiera cosa informe y grotesca). Y dice que era una "especie de mazamorra... que se servía en la misma Plaza Mayor [de Lima], en las fresquerias al aire libre que corrían a lo largo de uno de los portales. Dividíase en champús de leche y champús de agrio, haciéndose ambos de harina de maíz preparada especialmente, y siendo su más típico ingrediente el mote". Esto, en cuanto a la primera de sus formas; pues el champús de agrio lleva principalmente guanábana. 
-dijo un patrón de canoa-, -que lo cuelguen de la proa de algún buque a ese cangrejo.

- ¡Ay, Jesús! Si es un retrato el muchacho, de ño Lucas -dijeron dos malas cucas sobándole el omoplato. - Lo dicho - añadió un mulato-: como ustedes a una vaca. -Eso no, ño Calandraca

100 -repuso un carretonero-, que es prieto como chancaca.

- La cabeza es de pepino, la nariz muy langaruta: será un sabio, sin disputa -expuso un lego agustino. Pero un soldado ladino le replicó sin empacho, registrando bien el guacho y torciéndose el bigote: -IQué sabio ni qué virote!

110 Calle usté fraile capacho.

De mano en mano el chiquillo andaba entre tanto idiota. "Gordo está como pelota", era el común estribillo. Del fúlgido sol el brillo más y más se iba extendiendo; el barullo iba creciendo, nadie se entendía ya; y por aquí y por allá seguían yendo y viniendo.

Como el bochinche crecía y se enredaba el asunto, a fín de ponerle punto acudió la policía.

125 Cesó pues la algarabía,

107.- Guacho, o huacho: del quechua hnaccha, que significa "pobre y huérfano" según Diego González Holguín. Y, aún calificando el término como quechuísmo, Juan de Arona lo interpreta como "expósito, hijo de la piedra". 
como es de creerse, algún tanto;

$\mathrm{y}$ en un borrico, entre tanto, cargaron con hijo y madre.

Quién del muchacho era el padre. te lo diré en otro canto.

\section{CANTO TERCERO}

¿Quién de Hugo Blair ni de Horacio escucha ya los consejos? Vayan a un cuerno esos viejos con sus caras de topacio.

Y Moliére, y Moratin, que con Boileau y La Rosa bailaban la mariposa y jugaban al pimpín.

\section{Y Cienfuegos y Pincianos}

140 Luyandos y Gorostizas, que comían longanizas y se lavaban las manos.

Basta ya de tiranía: rienda suelta al pensamiento;

145 háblese así de un conventō como de una pulpería.

"Jorge Puccinelli Convers."

Contraigan frailes y monjas matrimonios clandestinos; adoren la cruz los chinos 150 y usen los cafres esponjas.

Las tímidas doncellitas por los ayes de algún ético sóplense un frasco de emético y háganse ánimas benditas.

Maldígase la virtud, preconícese el suicidio, y de la vida al fastidio arrimarle un ataúd.

Compárese al mar Adriático

160 con el río de la Chira, y dígase que ya expira todo turco con el viático. 
Fuera trabas y unidades, fuera puntos, fuera comas, Hablen los mismos idiomas los hombres y las nayades.

Pasó la clásica edad. ¡Maldición a su memorial Salud a la pepitoria y ¡viva la libertad!

Tales las máximas son de la romántica escuela, que en el siglo de mi abuela quemara la Inquisición.

Yo que ni al clásigo sigo ni al romántico tampoco, unas veces me desboco y otras pienso lo que digo.

Ora al profundo me bajo y a Luzbel declaro guerra, ora predico en la tierra odio mortal al trabajo.

Ya cual serio anacoreta al bello sexo excomulgo, oya le chanto un repulgo a la minga más eoqueta

Unas veces hago décimas, otras formo redondillas, otras compongo quintillas aunque salgan todas pésimas.

Y si me pone en apuro el maldito consonante, me agarro del asonante, que es más fácil y seguro.

186. - Minga es quechuísmo, derivado de la voz minkca o mincca; y equivale a contratar gentes para efectuar algún trabajo. Por tanto, no es el caso de la palabra, empleada en este verso.

Minga debe provenir de mingo, que se forma por abreviación de "Domingo" y designa a un galán muy apuesto y bien vestido. De donde se desprende que "la minga más coqueta" ha de ser una moza garrida y zalamera. 
Procedo, pues, en resumen, como mejor se me antoja, $\mathrm{y}$ entre tira $\mathrm{y}$ entre afloja conservo siempre el cacumen.

Y si esto no sabe bien

200 al criticón que me observa, que Dios lo guarde en conserva por siempre jamás, amén.

Mas te estoy viendo, lector, que tanto exordio te aburre. Hombre, jpor Cristo! discurre que otros lo hacen mucho peor:

pues para decir Longinos consumen pliegos y pliegos, $\mathrm{y}$ echan terribles reniegos, y dicen mil desatinos.

Paciencia: voy a cantar. Dejadme limpiar el pecho, pues ni la horchata de afrecho me ha podido mejorar. rasga sin miedo el charango, que si me sacas del fango te mando enterrar con palma.

Mucho preludias [pardiez! que se cansa el auditorio. $\widetilde{A}$ dó se halla el envoltorio digámoslo de una vez.

216.- Ricardo Palma estima que charango es un americanismo procedente del quechua, y lo define en los términos siguientes:

"La Academia trae charanga, como voz de uso reciente, aplicándola a las bandas militares de escaso instrumental. El charango de nuestros indios es una especie de pequeña bandurria, de cinco cuerdas que produce sonidos muy agudos. Probablemente la voz pasó de América a España, y en la travesía cambió la letra final. En cuanto a la pobreza de armonías musicales, allá se van la charanga y el charango".

Cf. Neologismos y Americanismos. 


\section{CANTO CUARTO}

Los castillos del Callao. en la época que se apunta, tenían de cola a punta cañones como cacao,

y morteros muy macizos, y algibes, ranflas y fosos, $\mathrm{y}$ torreones muy vistosos, y sus puentes levadizos.

Entonces, como de ley, se creía que esos castillos diez millones tres cuartillos le habían costado al Rey,

y que al ver Su Majestad las cuentas del Real Tesoro, exclamó: "Se han hecho de oro. No fué así mi voluntad".

El puente que unía a Lima se había bajado apenas, cuando un ruido de cadenas se apercibió por encima,

"Jorge Puccinelli. Gonverso"

$y$ eran ocho presidiarios que iban a hacer la limpieza, con cubos en la cabeza $y$ todos sus necesarios.

Al mismo tiempo el borrico, que al hijo y madre llevaba, pasito a paso asomaba por ese sitio el hocico.

235-238. - A la manera de las comedias del Siglo de Oro, y obligando a recordar su tardía adhesión a la causa realista, Manuel Ascensio Segura atribuye los errores de la administración colonial a los malos funcionarios e idealiza la equidad del rey.

Véase también los versos 345-346 y 355-360.

239. - Se refiere a uno de los puentes levadizos del castillo, ante el cual terminaba quizá el camino construído por el virrey O’Higgins. 
El orejudo animal y su abultado serón, de los presos la atención llamaron en general.

$Y$ uno de ellos, más travieso, detiene al burro por broma, descubre el serón, se asoma y se queda patitieso.

- ¿Qué hay? - preguntó el capataz-. ¿Son camotes o son yucas? ¿Sabe usté lo que hay, ño Lucas? Una zorra con su añaz.

Lucas se llega insensible, y al reparar en la carga sobre su frente descarga una palmada terrible.

-Es mi mujer, juoto a sanes! - dijo a sus otros compinches-. ¿No le habrán picado chinches con aquestos perillanes?

- Yamos, llevarla allá adentro y como pueda se entienda. Vaya: tú, suelta esa rienda $y$ entra al instante en el centro.

275

Y esto dicho, se apartaron cada cual por su camino, $y$ todos a su destino dentro de poco llegaron.

Cuál fué la infancia, no canta del héroe la musa mía. Presúmase cuál sería entre esa gente non sancta.

262.- Añaz, del quechua, zorrito. (N. del A.). Juan de Arona lo define en la siguiente forma: "Pequeño cuadrúpedo llamado también zorrillo, zorrino, y que acaso venga a ser esto mismo raposa. Es voz quichua. Tschudi la escribe con $\mathbf{s}, \mathrm{y}$ la traduce por varias especies de mefitis, zorrillo, etc". 
¿Ni quién me puede exigir? semejante cosa nunca? Quedaría mi obra trunca si tanto fuese a decir.

Basta saber que tan luego que tuvo la edad precisa, por todo el pueblo en camisa se le veía de andariego;

que lo pusleron a leer, que lo curtieron a azotes, $\mathrm{y}$ el $a b$ c y los palotes apenas pudo aprender.

Sin embargo jcosa raral no es de creerse, aunque se afirma, falsificaba una firma como lavarse la cara.

Que se limpiába los mocos con la falda del triquín. y hacía del corbatín gallitos y soplamocos.

Que predicaba sermones parado en una silleta, y llevaba la bragueta colgando hasta los talones.

Que las medias y zapatos, el vestido y el sombrero, los tenía como harnero y como cama de gatos;

Aunque estas prendas, es cierto, eran siempre el desperdicio de los mozos de servicio y éticos que habían muerto.

Que volteaba a zancadillas aún al preso más nervudo, y se comía el engrudo como quien sopla natillas.

Que ninguna faltriquera libre estaba de sus dedos; y que en trampas y en enredos le echaba pan a cualquiera. 
Que hacía guiños y yucas,

y huesillos y torcidos

a todos sus conocidos,

y hasta a su padre ño Lucas.

Que hablaba como cotorra

doscientos mil disparates,

330

$\mathrm{Y}$ con otros botarates

vivía siempre de gorra;

que andaba en zancos de palo

cargando navaja y honda, y que en toda la redonda era el muchacho más malo.

En fín, que cuando a su padre se le cumplió la condena, robándose una patena se fué a Lima con su madre.

\section{CANTO QUINTO *}

Ya del cañón de Ayacucho no se oía el estampido, ya hasta el último cartucho se había allí consumido, ganando renombre mucho el gran Ejército Unldo, y Bolivar en el mando reemplazaba al rey Fernando.

Ya los pobres chapetones, fuera de sus escondrijos, no sufrían mojicones de sus nietos y sus hijos;

(*) Trascrito en la recopilación póstuma de los Artículos, poesias y comedias de Manuel Ascencio Segura; pero allí se ha omitido la última octavilla (versos 451-458), que marca la transición al canto sexto.

345-346. - Recuérdese aquellos versos burlescos del presbítero José Joaquin de Larriva, aparecidos en plena efervescencia antibolivariana. el año 1827, y según los cuales "mudamos de condición" al quebrar la dominación española en la batalla de Ayacucho: "pero sólo fué pasando / del poder de don Fernando / al poder de don Simón". Con ellos tienen evidente semejanza éstos de Manuel Ascensio Segura, quien nos obliga a recordar que participó en dicha batalla al lado realista. 
ni por saquear sus doblones

se fingían revoltijos,

poblando los calabozos

con ancianos y con mozos.

355

360

A los pueblos infelices no se imponía ya cuotas de pesetas y perdices, ni se calzaban las botas con sus bienes y raíces los realistas y patriotas. Doquier, radiante su faz, asomaba ya la paz.

Rebozando placenteros en ideas seductoras

365

370 los patriotas verdaderos, cortas les eran las horas para hacer planes certeros de reformas y mejoras; y nuestra dicha y grandeza volaba toda cabeza.

Pocos serían aquellos que entonces calcularían que pensamientos tan bellos de mil modos se obstruirian;

355-360. - Igual equidad para juzgar las expoliaciones cometidas a la sombra de una bandera, durante las luchas por la independencia, aparece en un diálogo de La Espia, que Segura estrenó en 1854:

Regidor - Los godos, dice, que fueron autores de ese hecho inicuo.

Alcalde - No hay tal, fueron los patriotas; yo lo sé de positivo, y en seguida propalaron que los godos habían sido. El echarse unos a otros la culpa de sus delitos, diz que se llama en la guerra estratagema, artificio: pero sea como fuere. lo real y muy efectivo es que cada uno a su turno nos saca, mi amigo, el quilo. 
375

o a lo menos que nunca ellos realizados los verían; pero los que así pensaron sin duda alguna acertaron.

¿Ni quien había de creer que los mismos adalides que consiguieron vencer con la pujanza de Alcldes, al castellano poder en tantas sangrientas lides, 385 en tiranos se tornaran de la nación que ellos crearan?

Ninguno; pero el destino lo tenía así ordenado, y $\sin$ conciencia ni tino se vió después al soldado convertido en asesino y en déspota consumado, proclamando presidentes a un tiempo a tres pretendientes.

395

405

Y hubo de éstos un bribón que imploró en su desenfreno vergonzosa protección de otro ambicioso sin freno, 400 a quien vendió la nación

400 . dividiendo sul terreno,li Converso» y sujetándola al yugo de un extranjero verdugo.

Y también hubo peruanos que con infamia y mancilla, en sangre de sus hermanos empaparon la cuchilla,

395-402.- Alude al presidente Luis José de Orbegoso, que solicitó los auxilios del presidente de Bolivia, general Andrés de Santa Cruz, para sofocar el pronunciamiento efectuado en Lima por el general Felipe Santiago Salaverry; y que luego aceptó dividir el pais en dos estados, para constituir la Confederación Peruano-Boliviana. Al Protector no dedicó únicamente los juicios aquí expresados - "ambicioso sin freno", "extranjero verdugo"-, pues también le endereza sus dardos en una letrilla titulada La Santa Cruzada y en algunos extensos parlamentos de La Saya y Manto. 
y que besaron las manos al invasor cabecilla, entregándole joh ultrajel su propia patria al pillaje.

Doloroso es el recuerdo, pero de fama notoria.

Y si tal vez poco cuerdo lo traigo aquí a la memoria,

415 es porque importa este acuerdo para el hilo de mi historia, que se refiere a una prenda de nuestra civil contienda.

Entonces los malhechores que infestaban nuestra tierra se unían a los traidores, por la costa y por la sierra, y hasta sus hijos menores tenían lucro en la guerra... ¡Cuántos por ahí habrá de estos que, leyéndome, harán gestos!

Sí, los hay, y se rotulan ciudadanos beneméritos; y patriotas se titulan, sin servicios y sin méritos; y a otros godismo acumulan, siendo ellos todos pretéritos de la gloriosa ocurrencia que selló la Independencia.

Y esta casta vocinglera y de viles habitudes, ignorante y altanera, deprime las aptitudes de hombres de lustre y carrera y de públicas virtudes, y obtiene cargos y empleos conformes a sus deseos.

431. - Como los cantos de este poema aparecieron sucesivamente en El Moscón, y contra su autor se publicaba al mismo tiempo La Tarántula, debe presumirse que fué calificado como "godo" por su adversario. Por eso advierte la flagrante injusticia que supone acumular en unos las virtudes patrióticas, y ver en otros nada más que "godismo", no obstante que al sellarse la independencia quedó éste concluído. 
¿Quién jamás le hubiera dicho a uno de esos presidiarios, que vivían de entredicho con ricos y proletarios, que de la suerte el capricho llevaría a Comisarios y a otros puestos a su prole, a pesar del tole-tole?

Pero el tono va alto, Pedro; baja un poco que estoy ronco, contempla que nada medro 455 de cocobolo 0 de cedro. Sigamos en eco bronco la narración comenzada haciendo aquí una parada.

Cuando Lucas se encontró $\sin$ beneficio ni oficio, tornó a su antiguo ejercicio: esto es, a robar volvió. Y cebado en este vicio,

465 año después resolvió y entró a servir desereno.

Cuando indicaba las horas su voz hueca y sepulcral, de la cruz hacían señal

$470 \quad a$ los niños sus tutoras; y aún diz que les daba el mal a más de cuatro señoras, porque siempre sus pregones augurio eran de ladrones. -tal nombre le puso a su hijoasistía a un desvalijo como guía y como gancho; y tan callado y prolijo era en cualquier zafarrancho, que la prenda que empuñaba jamás su dueño la hallaba. 
Por postre y fín, la justicia lo persiguió sin descanso, y estuvo algún tiempo manso no embargante su pericia; pero el favor de otro ganso lo puso pronto en franquicia, y temiendo por su cuero se dedicó a yerbatero.

Empuñando una costilla y sobre una burra manca, a quien formaba en el anca sangionosa chacarilla, desde el Puente a la Huaquilla, y desde allí a la Barranca, repartía Pancho alfalfa aunque con alguna escalfa.

Mil gustos daba el mirar la recua que Pancho arriaba: con un grito la paraba, con otro la hacía andar: después el látigo alzaba y haciéndolo resonar "Azaquió burro", decía, y al gran galope partía.

3 Entró a echar yerba una vez a una casa de comercio "y escondió dentro de un tercio" tres platos y un almirez; el portero, don Lupercio, se los quitó de un revés, $\mathrm{y}$ temeroso el muchacho se fué con su padre a Huacho.

Aunque hijo de negro congo no era Lucas una mula, que ni siente ni calcula, ni tampoco un indio pongo: leía corriente en la Bula y hasta escribía un diptongo, lo que le fué suficiente para meterse a escribiente.

Y dió la casualidad que su amo fuese un Actuario que vivía en choque diario 
con toda la vecindad; a Pancho también salario le daba sin mezquindad, para que jurara en falso aún contra el que iba al cadalso.

Y salió Pancho tan diestro $y$ de tan malas entrañas, que en ardides y marañas le daba quince a un maestro.

535 En el pueblo, por sus mañas, le pusieron Ambidextro, y un célebre papelista lo apellidaba El Legista.

Aunque tan en grande le iba, quiso otro teatro elegir, y una noche, sin sentir, robándole al pobre escriba hasta el gorro de dormir, echó culatas arriba.

$545 \quad Y$ al saber Lucas este hecho brincó de rabia y despecho.

$Y$ dejando al ministril de quien comía el puchero, se metió de montonero

550 en la discordia civil.

Si pasó o no de ranchero, o si finó de fusil, en una horca, o en su cama, es lo que no habla la fama.

555 Pancho vestido de fraque, con botas y con chaleco, y tieso como un muñeco, Y siempre tan badulaque, volvió al Callao algo enteco,

560 y al mirarlo ya tan jaque los de ese pueblo y de Pisco, lo llamaban don Francisco.

El hijo del capataz, de este modo transformado, se puso a servir al lado de un famoso juez de paz, 
que lo estimó en alto grado por suficiente y capaz, para enmiendas, raspaduras y otras dos mil travesuras.

Creyéndose en salvaguardia trabajó una vez cierta obra, que molestando de sobra a unos soldados de guardia, le hicieron cierta maniobra con el frente a retaguardia, que lo titula de esa hecha. Pancho sácate la mecha.

\section{CANTO SEPTIMO}

\section{Por San Francisco el seráfico,} de quien fué mi padre acólito, que cunque no precio de insólito" ni con mi lira hago tráfico, tengo de echar hoy la brújula a composición esdrújula.

Y juro por cuantos trápalas en el mundo tienen hálito, que de fraile me echo el hábito - me meto a peón de Huápalas si aquesta parte de mi épica no la concluyo sin réplica.

Nada importa que un narcótico me sople dentro el ventrículo cierto pedante ridículo,

596. - Huápalas es el nombre de una hacienda situada en la provincia de Piura. Su caserío contaba a la sazón cerca de 300 habitantes. 
que en metro más estrambótico a Longinos y Gérónimos pretende hacerlos sinónimos.

Llámeme en buena hora zángano, y tuerto, y bruto, y ovíparo; yo le digo que es un pícaro, un asqueroso carángano, que se puede sin obstáculo botarlo en un receptáculo.

Y que hombre tan poco sólido, o más bien un catecúmeno, retoño de un energúmeno, lleno de infamia y estólido, 615 que un hombre que todo es cábulas no puede hablar sino fábulas.

$Y$ al que me diga que es crítico y ortográfico, y ecónomo, y calígrafo, y astrónomo, 620 diplomático y político, le contesto: ¡Voto al chápirol Que es un cándido, un gaznápiro.

De otra manera su cálamo no escribiera aquella epístola que ha hecho la horríble fístola con que ha infestado su tálamo, y cuya hediondez ya es pública aún en toda la República.

Con proceder tan horrísono hasta para indios indómitos, y que a un cristiano da vómitos, sólo él puede estar unísono. Que es simple per omnia soecula molécula por molécula.

Allí está sino el periódico de las inflamables líneas y de las materias ígneas, que hasta al lector más fosfórico le causan sueño sus fárragos tan enjutos como espárragos.

Pues sólo el autor magnífico que ha hecho sus tripas termómetro, y quien sabe si barómetro 
$\mathrm{u}$ otro instrumento científico, puede sin darle parálisis hacer con calma su análisis.

Pues la tiene más que Sócrates tomando el tártaro emético, muchísimo mós que un ético cuando lo pulsa su Hipócrates, sin embargo que hasta el tuétano le es fastidioso el peruétano.

No falta por ahi empirico que dice que está perlático, y que se ha vuelto manlático por hacerse poeta lírico, y que le va a dar un cólico sin tomar éter vitriólico.

Mas dejemos a este fósforo que escriba más que Escalígero - que se vuelva voltijero o se zambulla en el Bósforo, - que cause más escándalos que un ejército de vóndalos.

$Y$ supuesto que de mi émulo se da factancioso el título en el próximo capílulo, porque siento éh pullse trémulog on lo haré ver con menos máscara quitándole más la cóscara.

653-656.- Según Luis Alberto Sánchez (cf. El señor Segura, Hombre de teatro : p .105): "no parece aventurado afirmar que Segura se pudo referir a don Felipe Pardo, y concretamente a su composición $A$ mi hermano ãon José Pardo, epistola en versos esdrújulos, escrita desde los baños de Yura (lo que explicaria la alusión a perlático y parálisis) para acompañarie La Laimpara (lo que explica el empleo del giro "hacerse poeta lírico"), además que lo de émaio calza con la polémica en torno a El Espejo de mi Tierra y otras más".

Pero tal aserto es, justamente, aventurado: pues, en armonia con lo sustentado por el propio Luis Alberto Sánchez, la paternidad de Lima contra el Espejo de mi Tierra corresponde a Bernardo Soffia, periodista y militar "parduzco"; y las alusiones de Manuel Ascensio Segura aluden en forma clara al mantenedor de un periódico local en cuyas columnas se le denostaba ("llámeme en buena hora zángano y tuerto, y bruto, y ovíparo"). 


\section{CANTO OCTAVO}

La conquista o la invasión todo lo había variado, y la Confederación, como sistema adoptado, 675 con un gobierno absoluto cubría al pueblo de luto.

Pancho abrazó con ardor el extranjero partido; fué su espía y delator

$680 \mathrm{y}$, como tal, atendido con la plaza y la propina de amanuense de oficina.

Tan hinchado como un pavo lo puso ese destinillo, y sin tener un ochayo se hizo a más el cupidillo ulmibarado y ficcioso del que llaman sexo hermoso.

Talega, entonces, de amores, 690 le pusieron los mozuelos porque echaba a todas flores, a todas pedía celos, y a todas enviaba cartas con disparates a sartas.

695 Y a una graciosa morena, algo abultada de popa, parienta de una chilena que allí lavaba a la tropa,

700 sus ayes y sus suspiros.

Más dura que un algarrobo era la tal Dulcinea; trató al amante de bobo; él le dijo vieja y fea, y quiso gozar violento su atrevido pensamiento.

Pero ella tanto gritó y formó tanta algazara, que la gente que acudió, 
echando su culpa en cara al causante de tal acto, lo hizo casar ipso facto.

En los libros del amante no se hallaba esta receta;

715 sin embargo como un guante lo puso la manganeta, y cargó con su petaca sin otro toma ni daca.

720

Se hallaba el nuevo consorte más calato que San Juan, sin recurso ni resorte para conseguir un pan, y $\sin$ cama en qué acostarse, ni una silla en que sentarse.

725

Pero pronto halló el remedio para amueblar bien su casa. Echó por la calle en medio, y diciendo "Todo pasa", robando iba a la sordina los muebles de su oficina.

Lo cual, sabido que fué al instante por su jefe, mandó que de un puntapié las pusieran al mequetrefe,

735 sin más bromas ni más citas, en la calle de patitas.

Así se hizo luego luego, y el menguado cagatinta tomó las de Villadiego de una manera sucinta, amenazando entre dientes aún a mudos expedientes.

$Y$ entrampando a troche $\mathrm{y}$ moche, estuvo dado de baja hasta que llegó la noche

716. - Manganeta : americanismo, equivalente a pasada, treta, broma. (N. del A.).

720.- Según Juan de Arona, calato significa "desnudo, en cueros. Es voz quichua, mucho más usada en el interior que en Lima". 
en que al són de pito y caja

se proclamó de mandón

un Jefe de la Nación.

Pero como en este mundo no hay dicha sin contratiempo, a ser volvió vagabundo dentro de muy poco tiempo, porque el Gobierno Vidal lo echó otra vez al corral.

755

760

A la silla disputada subió en seguida Vivanco: Pancho probó la coartada y también volvió a su banco, causando así muchos males a los constitucionales.

Como todo a su entender al Directorio afirmaba, él era quien más gritaba contra el de otro parecer, y llamaba al Director el Hércules salvador.

Todo iba perfectamente, cuando cierta nubecilla que apareció de repente mostró al invicto Castilla, que a su Patria debería engrandecer algún día.

Y creciendo más y más esa nube bienhechora, 775 y dejando gente atrás, ingrata $\mathrm{y}$ perseguidora, avanzaba a darnos leyes a la Ciudad de los Reyes.

747-748.- Se refiere al general Juan Crisóstomo Torrico, jefe de un pronunciamiento militar contra el presidente don Manuel Menéndez, efectuado el 16 de agosto de 1842. Su proclama acentuó el tono personalista de las pugnas caudillescas, pues en ella declaró "aceptar" la Jefatura Suprema que por si mismo tomaba. 
Al oir Pancho estos detalles se puso a hablar como loco, por las plazas y las calles, contra el hombre que hacía poco era más grande para él que el arcángel San Miguel.

El gobierno tuvo aviso del faltamiento del mozo, $\mathrm{y}$ viendo que era preciso meterlo en un calabozo, dispuso que así se hiciese sin que nadie lo sintiese.

Pero Pancho olió la cosa y discurrió en tal acuro que ponerse en polvorosa sería lo más seguro, porque odiaba a Casas-matas desde que anduvo allí a gatas.

Resuelta pues la partida, sin andar con muchas fiestas ni hacer otra despedida, se echó la maleta a cuestas y poniendo el rumbo al sur le dijo al Callao IAgur!

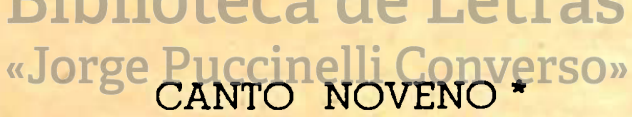

¿Quién fué Rómulo? Un ladrón.

805 Quién fué el grande Napoleón? ¿Quién fué Viriato? Un cuatrero. Un corso de cargazón, como consta al mundo entero.

¿Qué fueron los ascendientes de los reyes ostrogodos?

810 Vagabundos insolentes que, con uñas y con dientes, sqquearon los pueblos todos.

(*) Aparece como "canto veinte" del poema en la recopilación póstuma de los Artículos, poesías y comedias de Manuel Ascencio Segura; pero allí se ha omitido una quintilla (versos 888-892). 
Saúl, David, ¿quiénes fueron?

Unos destripaterrones

que, cuando al trono ascendieron, en mil apuros se vieron para atarse los calzones.

820

¿Y quién es el que sujeta al nuevo imperio de Haití? Un pobre diablo, un trompeta, un negro con tanta jeta, un risible maniquí.

¿Y de los grandes y reyes que en algunos pueblos rigen a los hombres como bueyes, y a su arbitrio dictan leyes, ¿cuál, en fín, será el origen?

Todos son nietos de Adán, sea cual fuere su testa: todos viven con alán, todos vienen, todos van: esta es mi única respuesta.

Más claro, escúcheme sólo el que más noble se nombro: 835 desde un polo al otro polo, un blanco, un negro o un cholo no és loira cosa quel un hombre

a quien cualquier accidente hace pobre o hace rico, 840 conde, duque o presidente, quitapelos o sirviente, o muy sabio o muy barrico.

Lo que al hombre da nobleza es la virtud y el talento; lo de la sangre es simpleza, es espuma de cerveza que se evapora al momento.

Así es que yo no extrañara 850 que el heroe que hoy y a puestos altos llegara si fuese sabio y honrado. 
Porque nadie responder puede de ajenas acciones, ni a sus padres escoger, que si esto pudiera ser todos fueran Napoleones.

$\mathrm{Ni}$ por dimes y diretes, - motes que nada valen, andar con otro a cachetes; pues los más caballeretes con ellos entran y salen.

El Largo, el Calvo, el Valiente, el Demonio, el Hechizado, el Gordo, el Simple, el Prudente, el Sin-Tierra, el Impotente, el Bastardo, el Emplazado,

el Negro, el Batallador, el Tartamudo, el Gotoso, el Monje, el Conquistador. el Pajarero, el Terror, el Casto y el Lujurioso:

sobrenombres son aquestos de reyes y emperadores, que ni dieron manifiestos ni se mostraron molestos. por semejantes favores.

Y allá, en la tierra de España, cuya lengua estoy hablando, aún se dice Tío Castaña, Tío Roña, Tío Lagaña, Tío Porra y Tío Carando.

$Y$ hay muchos hombres de bien 885 que al oir nombrar su apodo responden al punto: ¿Quién? Porque, ciertamente, creen que se llaman de ese modo.

$Y$ aquí mismo, no se pica por esos motes tampoco ése a quien llaman Ño Antica, Y mucho menos Na Mica, Ño Cariche y Ño Polloco. 
Ni se han mostrado mohinos

895 por tan lisos arrumacos los Regalados, Longinos, los Músicos, los Pollinos, los Zorritos, ni los Pacos.

$Y$ hacen bien: porque ninguno

900 pierde el honor y la fama si no daña o roba a alguno, como le sucede al tuno que Peli-muerto se llama.

$Y$ el motivo por el cual se conoce así a ese tonto después lo diré al mortal, pues no soy ningún costal para vaciarme de pronto.

$Y$ si por esto se atufa el que me presta atención, 910 y rabia y potea y bufa, eche el poema a la estufa y nunca lea El Moscón.

\section{CANTO DECIMO}

De San Francisco en el macho anduvo Pancho una legua pero allá por la Menacho cabalgó sobre una yegua que le arrebató a un muchacho.

$Y \sin$ montura ni freno, ni un medrugo para fiambre, ni un poncho para el sereno, aunque en cuerpo y muerto de hambre, llegó a Jauja sano y bueno.

$Y$ pasando a ver allí de la Junta a los tenientes, con fingido frenesí y ademanes sorprendentes, les habló impóvido así:

-Señores, Vivanco ha muerto: ya no existe el Directorio 930 que en sangre y luto ha cubierto nuestro hermoso territorio. - ¿Es posible? ¿Será cierto? 
Todos a un tiempo exclamaron, y repicar las campanas sin más dilación mandaron, y fervorosos Hosannas en alta voz entonaron.

Tal explosión de alborozo dejó a Pancho medio inerte. -Escuchad -gritaba el mozo. $Y$ ellos gritaban más fuerte, embriagados con el gozo.

La calma, en fín, reemplazó la deshecha tempestad, Pancho el pecho se limpió, y mostrando gravedad de esta suerte prosiguió:

- Señores todo es fícticio; lo que acabo de exponer iba a decirlo de oficio si ese tremendo Poder lo hubiera llamado a juicio.

"Media hora más, y Vivanco durmiera con Belcebú, pero a bien que no soy manco: si lo encuentro en el Perú ipor Dios que lo desbarrancol

"Porque han de saber usías que si ha abortado mi plan las faltas no han sido mías, sino de un vil sacristán que sobornó a mis espías.

Dijo, y dejólos tan mudos a todos como un peñasco, pues aunque eran ya barbudos se avergonzaron del chasco como unos pobres tetudos;

no obstante, sin inmutarse ni enderezar más pregunta, cuando iba Pancho a marcharse le dijeron que a la Junta fuese al punto a presentarse. 
Para dejar, pues, cumplida

la orden de aquellos mandones, en la yegua consabida se puso de dos tirones de ese pueblo en la salida.

$Y$ atravesando caminos llegó, y contó a Su Excelencia 980 mentiras y desatinos, teniendo a más la insolencia de suponerse destinos.

- ¿Y usted qué plaza servía? -le preguntó el General.

- Señor, de Comisaría era primer oficial.

-Vaya a la Secretaría.

Pancho lleno de contento por el feliz resultado de su loco atrevimiento, al Secretario de Estado se presentó en el momento,

quien lo tuvo en su retrete sirviéndole de ordenanza, de su espía y adulete, de su criado de confianza, de "plumario y de alcahueterverso"

y quien fijó la carrera del hijo del presidiario, sin saber lo mal que hiciera, nombrándolo Comisario cuando dejó la cartera.

Figúrese aquí el lector, 1005 que conoce a Pancho Empuña, cuán a su gusto y sabor no encajaría la uña como empleado pagador,

sin más cargos ni más datas, ni más fianzas que su orgullo, pues sólo a los papanatas en los tiempos de barullo se obliga a esas pataratas. 
A ninguno hacía un pago si no partía con él.

-Vaya, venga para un trago - le decía a un Coronel con lisonja y con halago.

Mas si al que hacía el abono

1020 era un pobre subalterno, cuando éste aflojaba el mono, firmar le hacía el cuaderno con imperio y desentono.

Y si acaso resistía la rapiña o la pitanza, -No hay dinero -le decía-; lleve usted una libranza contra otra Tesorería.

En fín, en dos o tres meses que administró los caudales, sin sustos y sin reveses se hizo de miles de reales, de caballos y de reses.

\section{Bi cuandò sele quitó Letras} la intervención en las rentas en descubierto salió : porque en sus trampas o cuentas nunca ató ni desató.

La fortuna, sin embargo, caprichosa e inconstante, de los que dieron tal cargo a este famoso tunante, hará durar el letargo;

y lo hemos de ver pintar todavía en esa Lima do se le ha visto cargar un tercio de alfalfa encima $y$ arrear burros y robar. 


\section{CANTO ONCENO *}

La doméstica discordia había ya terminado,

1050 y vuelto el país al reinado de la ley y la razón. Todos en paz y concordia, olvidando sus desgracias, rendían al cielo gracias por tan feliz situación.

1060

1065

1070

1075

El generoso guerrero que al Estado dirigía, los partidos extinguía con firmeza sin igual; $y$ el resplandor de su acero y sus increíbles victorias, no le daban tantas glorias como su buen natural.

Bendiciones y saludos todos los pueblos le enviaban, $y$ todos de él esperaban que hiciera a su Patria el bien. La fama de sus virtudes atravesando los mares, hasta en extraños lugares se hacía escuchar también. tras

El noble entusiasmo que a mi alma le inspira tu gloria, Castilla, quisiera cantar; pero no me es dado del vate la lira con ecos sonoros y acierto pulsar.

En son destemplado permite, no obstante, que llegue a tu oído mi grato sentir, y pura y sincera mi voz se levante cual parla de un niño que empieza a decir.

1080

La paz y ventura que goza el peruano a tí se te debe, preclaro varón, que fuíste en el campo terror del tirano y humano y prudente después de la acción.

(*) Como "fragmento del canto onceno" aparecen los versos 10481083 en la recopilación póstuma de los Artículos, poesías y comedias de Manuel Ascencio Segura. 
1085

Prosigue rigiendo tu Patria, Castilla, y dándole vida, contento y salud, que cuando te baje la ley de la silla, la Historia hará eterna tu heroica virtud.

Mas volviendo a atar los nudos

1090

1095 del comenzado poema, que me trae como al que rema en una agitada mar, diré que Pancho entre escudos, entre alhajas y otros huesos, tendría sus diez mil pesos más o menos que contar.

Al verse pues entre gentes de poder y de riqueza, se le voló la cabeza y se juzgó un gran señor;

$1100 \quad$ y como los más pudientes adornó su casa toda con muebles de última moda $y$ de un lujo superior.

Compró caballos y criados,

1105 armas $y$ ricos arneses, Y sólö a sastres franceses daba su ropa a coser. Diez oedoce convidadosnverso" que asistían a su mesa, a lo criollo y a la inglesa se les daba de comer.

El burdeos, el oporto, el madera y el champaña, Y varios vinos de España corrían cual río allí;

1067-1082.- Estos dieciséis versos dodecasílabos son los únicos de arte mayor en todo el poema, y constituyen una evidente interpolación. En ellos se desenvuelve un apóstrofe laudatorio al general Ramón Castilla, a la sazón presidente del país, y a quien tal vez quiso el poeta hacerle llegar un testimonio de su agradecimiento, porque lo repuso en la secretaría de la subprefectura de Piura, a despecho de las insidiosas acusaciones de sus enemigos locales. 
y nadie quedaba corto

en lisonjas para el dueño, a quien parecía un sueño el verse tratar así.

La modista más nombrada vestía a su cara esposa; esencias de aroma y rosa perfumaban su carmín.

1125 en Chorrillos un buen rancho, $y$ en el concepto de Pancho nada le faltaba, en fín.

Mas lo que hasta ahora no he dicho. y es lo más lindo del caso, porque fué su primer paso cuando entró en la capital, es que se puso al capricho lacia y rubia una peluca, para taparla a su nuca lo de lo negro bozal.

Y que luego en la Comedia se presentó asi contrahecho, en palco y muy satisfecho, el hijo del capataz;

1140 y que al menos hora Y media durarían las palmadas, los silbos y carcaiadas que allí causó este disfraz.

Los diarios al otro día 1145 referían la ocurrencia y de Pancho la ascendencia, $y$ su orgullo y candidez; y en la ciudad se decía que el público con acierto el nombre de Peli-muerto le había puesto a la vez.

Pero Pancho, tan conforme, en tertulias $y$ paseos complacía sus deseos sin echar la vista atrás. Puesto de gran uniforme con bordados y pinturas, pensaba que las figuras no se destrozan jamás. 
-Para realzar su importancia, sobre su antiguo apellido se puso otro conocido en la Historia del Perú. Con ostentosa arrogancia hasta a sus jefes hablaba, y a los demás los trataba cual príncipe, tú por tú.

Las onzas y pesos duros, cuando concurría al juego, le ofrecían luego luego sin mezquindad, los del rol. Hombres notables y oscuros le hacían visitas diarias, y aún le tarareaban arias en gringo $y$ en español.

Sin haber jamás estado en ningún colegió ni aula, porque siempre fué tan maula que no llegó al quis vel quid como un sabio era escuchado, aunque en su charla pedante tomara al Cairo por Gante y a Bernardo por el Cid.

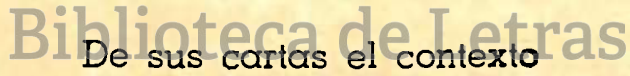
le copiaba al Presidente, y este cargo de escribiente lo hinchaba como un tonel: porque bajo este pretexto se daba aires el zoquete que todo en el Gabinete se consultaba con él.

Daba recomendaciones a jefes y subprefectos, y escribía a los prefectos dos o tres veces al mes; en las fiestas y funciones disputaba los asientos, y hacía mil movimientos con las manos y los pies.

Entraba y salía a Palacio como quien entra en su casa, y en todo metía baza 
porque se creía el non plus.

1205 No andaba nunca despacio, aparentando quehaceres, y sólo a lindas mujeres atendía el zampamplus.

Ultimamente, en la cumbre

1210 se vió Pancho de la dicha, sin recordar la desdicha de su vida juvenil.

Mas !quién sabe si la lumbre que ahora lo alienta y halaga,

1215 si del todo no se apaga queda en moco de candill

\section{CANTO DOCE *}

El plan que mejor se traza, y más llena y satislace, como el humo se deshace cuando más firme se cree:

$1220 \mathrm{y}$ el que hoy se mira mandando ejércitos y naciones, fugitivo y $\sin$ calzones, tal vez, mañana se ve.

Allí está st no la historia.

1225 que "debe ser brespejol Converso" en que el mozo y en que el viejo han de ver con avidez; allí se encuentran monarcas por las nubes y los suelos, $\mathrm{Y}$ allí están para modelos Luis Felipe y Carlos Diez.

1207. - Juliana, impulsada por su madre a tolerar los galanteos del afrancesado Don Alejo, dice (cf. Na Catita : Acto I, escena V) : "Ni me he de casar tampoco con el otro zampamplus". La palabrita, que apa. rece en diversas poesías y piezas costumbristas de la época, debió ser muy celebrada y expresiva; pero no la glosan, ni Juan de Arona, ni Ricardo Palma. Su significado obvio se emparenta con "zampalimones" - cándido.

( ) Como "fragmento del canto quince" aparecen las euatro pri. meras octavillas (versos 1211-1242) en la recopilación póstuma de los Articulos, poesias y comedias de Manuel Ascencio Segura. 
En este pícaro mundo todo es, pues, contradictorio, todo vano e ilusorio, todo $\sin$ seguridad;

pero el hombre no se cuida de una verdad tan patente, y es en la dicha insolente y humilde en la adversidad.

Otro ejemplo es Peli-muerto de la inconstancia mundana: de la noche a la mañana cual un globo se elevó; pero al verse tan arriba perdió el pobre la chaveta, y dando otra voltereta vino al suelo y se estrelló.

Gastado todo el dinero que tuvo mal avenido, y después de haber vendido aún su mejor peluquín; para poder conservarse con bambolla todavía, Foncha sobre roncha hācía a Pedro, Sancho y Martín . "Jorge Puccinelli Converso"

Perdía en el juego miles, por vanidad y al tanteo, y hasta jugara el empleo si quisiera algún tahur; mas como nunca pagaba a sus muchos acreedores no había ya jugadores que corriesen ese albur.

Viendo que nadie le daba al contante ni un cuartillo, discurrió un medio sencillo para poderse acorrer: tomaba efectos al fiado, se entiende a subido precio, y nunca faltaba un necio que los quisiese perder. 
Hacía pedir alhajas a las tiendas, para verlas, $\mathrm{y}$ empeñarlas y venderlas 1275 por otra mano después; $\mathrm{y}$ con insultos $\mathrm{y}$ enredos respondía a los teclamos que hacían de ellas sus amos en guarda de su interés.

Para la compra de sueldos le fiaron dos gringos plata, pero les metió la pata como a enemigos de Dios, presentóndoles recibos, 1235 que falseaba con acierto, de empleados que habían muerto hacía ya un año o dos.

Logró una vez ser nombrado como albacea dativo.

1290 y cuentas de vocativo dió solamente al concluir. Los herederos quedaron todos tocando tabletas, y se sopló lás pesetas 1295 del difunto sin sentir.

Otra vez, una señora Letras le confió unos documentos. de importe de algunos cientos $1300 \quad$ él se los dió por perdidos, Y vendiéndolos con daño sacó el vientre de mal año apropiándose el metal.

1305

La sencilla interesada, dando crédito al bergante, mandó poner al instante de la pérdida un cartel; pero Pancho al otro día, para burlar este empeño, 1310 bajo la firma del dueño contradijo ese papel.

La robada, ardiendo en ira con hecho tan temerario, le dijo a Pancho en un diario 
que era un falsificador; e hizo que dos escribanos diesen testimonio de esto, quedando así manifiesto el infame usurpador.

El Correo y El Comercio contaban al otro día tan insigne picardía con notable indignación; y nombrando a Peli-muerto con sus pelos y señales, en letras como tamales Jo apellidaban ladrón.

A poder de la señora los documentos volvieron, pues los jueces los pidieron por medio de un alguacil; al comprador le dió Pancho un pagaré de esos pesos, y dados tenía de esos cuando menos unos mil.

Hasta al mismo Presidente le hizo muchísimas puercas, pero aquel sin más altercas Jompuso de oro y lazub dando al instante sus órdenes, pero de un modo muy serio, de que en ningún ministerio se diese entrada al gandul.

En los bailes, las señoras huían de él como apestado, $\mathrm{y}$ era siempre desairado aún pidiendo por merced. $Y$ hubo padre que le dijo: -Caballero, usted no exija, porque no baila mi hija con un pillo como usted.

Llovían contra él las quejas, las demandas y las citas, pero salía de cuitas no dando cara jamás. 
No atravesaba una calle sin que alguien no le dijera "petardista" y "calovera" por delante y por detrás.

Aburrido y acosado con golpes tan incesantes, resolvió salir cuanto antes aunque fuese al Macará. Suplicó que lo nombrasen de Secretario aquí, en Piura, cosa que creía segura por lo que ya se dirá.

En seguida con empeño solicitó la Intendencia, pero a todo Su Excelencia respondía con tesón:

- Mientras obtenga yo el mando. y pueda no ser dañino, no tendrá ningún destino ese zambo picarón.

Entre tanto el pobre diablo continuaba, en los aprietos $y$ otros sustillos secretos de su vida conyugal; por to que, de cualquier modo, quiso salir de ese infierno y obtuvo al fín del Gobierno un permiso temporal.

No obstante, en el pasaporte se hizo nombrar Intendente, engañando así a la gente sin miramiento ningún, y a fín que no lo arraigasen por sus deudas en la corte, 1390 en donde ya era su porte tan negro como el betún.

Dando un adiós a sus trampas subió por último al coche, y del Mazzepa una noche pasó a bordo el baladí; 
y al cabo de cinco días

fondeó en Paita con buen viaje,

y sin pagar el pasaje

se vino corriendo aquí.

\section{CANTO TRECE}

1400

1405

1410

1415

1420

1425
En el canto que acabó dije, si mal no me acuerdo, que cuando pensó dejar la capital Peli-muerto, creyó como de cajón que le diesen el empleo de Secretario aquí en Piura, y que bajo este concepto se lo pidió al Presidente, que le contestó: - No quiero.

Mas como hasta ahora no he dicho el motivo 0 fundamento en que apoyó esta esperanza que se deshizo tan presto, pasaré con tu permiso, querido lector, a hacerlo. Pero no será demás que te prevenga al intento, que aunque me llames difuso, y pesado, y majadero, "Y me cpongas más apodoserso" que los del gran Peli-muerto, no por eso has de evitar que yo te encaje en el cuerpo la sucinta relación de sus memorables hechos, durante el tiempo que ha estado aquí, comiendo y bebiendo; pues no obstante que la sabes has de escucharla de nuevo;

1399. - Recuérdese que el adverbio "aquí" designa a Piura, donde La Peli-Muertada fué escrita e inicialmente publicada.

1428-1429. - Manuel Ascensio Segura recapitula en este canto -y los siguientes- una serie de sucesos notorios para los vecinos de Piura; y para evitar que su "pobre Epopeya" se dilatara enojosamente, baja el tono inicial de la sátira. Parece trocarse en cronista, y cita testigos y circunstancias públicas de cuanto refiere, para que no se le juzgue fabulador. 
1430 esto es, si te da la gana, que si no, nadie en el pecho te ha de poner un puñal a fín de obligarte a ello, ni a mí para que no escriba

1435 cuanto quiera, malo o bueno, aunque ninguno haga caso de mi prosa o de mis versos. Y acá, para entre los dos, si he de hablarte lo que siento, tampoco me importa mucho que tú, o cualquier mostrenco de aquellos que a todo le hallan sin saber por qué su pero, mire mi pobre Epopeya con cariño o con desprecio; - la haga tantas tiritas como hebras tiene de pelo de Peli-muerto el casquete; o envuelva con ella ungüentos; - la corte para moldes de mampuchos o chalecos; - la destine indignado a cierto oficio secreto, cuyo nombre no se dice 1455 sino con muchos misterios, como si fuera delito el llamar a Pedro Pedro. Sentado esto, buenas noches nverso"

1460 Pues señor, cuando le puso Pancho el punto, a dicho empleo, se encontraba en el Callao un coronel, que el Gobierno acababa de nombrar para regir estos pueblos,

1451.- Mampucho, mampuche, o bambuche es, según opinan algunos, corrupción del it. "bambache". Designa "cada una de las figurillas de barro vidriado que los antiguos solían poner en las balaustradas de las azoteas"; y, por asociación, se lo aplicó tal vez a la cobertura protectora de tales figurillas.

1463-1464. - Se refiere al coronel de infantería don José Joaquín González, nombrado Gobernador de la provincia litoral de Piura en mayo de 1847, para reemplazar al coronel Alejandro Deustua, que había ejercido el cargo desde noviembre de 1844 . Por su adhesión al Directorio había merecido ese grado el 11 de diciembre de $1843, y$, producida 
y con el cual era amigo

Peli-muerto, de sombrero....

A éste, pues, se le colgó

como aldabón el camuezo;

1470

e hizo muchísimos viajes

desde Lima, para verlo,

y le lloró y suplicó

que le pidiese al Gobierno

para Secretario suyo,

1475

por que no hallaba otro medio

para librarse de jueces,

de amenazas y de enredos.

El Coronel, condolido

con tales llantos y ruegos,

1480 le ofreció que así lo haría;

y su palabra cumpliendo

dió los pasos necesarios

en todos los ministerios,

teniendo el pesar de ver

1485 desatendido su empeño;

y hasta el mismo Presidente, sabedor de sus deseos,

lo hizo llamar y le expuso

las gracias de Peli-muerto

1490

de un modo tan minucioso,

$y$ en un tono tan severo,

que se arrepintió de haberas

tal disparate propuesto.

1495

Con estás mismas palabras

me refirió este suceso

el Coronel supradicho,

que está gordo, sano y bueno;

y me puede desmentir

1500 En tanto, todas las cartas

hablaban del nombramiento

como negocio concluído;

así es que al llegar al puerto

el nuevo Gobernador

1505

sin traer consigo al sujeto,

la restauración constitucional, estuvo varios meses sin colocación; el 7 de julio de 1846 le fué confiada la jefatura del Batallón Marina, de la cual fué trasladado a la gobernación de Piura y en 1850 a la prefectura de Ancash, de la cual fué separado el 20 de marzo de 1854 en atención a su propia renuncia; y, fuera ya del servicio activo, el año 1871 ejerció en la Cámara de Diputados la representación de la provincia de Huaraz. 
fué general la extrañeza

por este acontecimiento;

hasta que la causa todos al otro día supieron.

1510 Peli-muerto llegó a Paita al cabo de mes y medio, $y \sin$ olvidar su oficio de pintor y de embustero, 1515 aseguró con descaro que traía una comisión de Hacienda por el Gobierno, la cual le había obligado a venir a este destierro, a cuya fábula muchos incautos dieron asenso.... Después con colchón y todo se vino a vivir derecho adonde el Gobernador,

$1525 \quad \sin$ su previo asentimiento lo que le supo a este Jefe a chicharrones de sebo, pues no había entre él y Pancho tanta confianza para eso;

1530 y lo que sufrió callado por no agarrar al muñeco y ponerlo en media calle con escándalo del pueblo.

De este modo se expresaba

1535 dicho jefe en aquel tiempo, de lo que doy testimonio aunque registro no tengo, pues se lo oí varias veces cuando se hablaba sobre ésto.

1540 Apenas había llegado a esta ciudad Peli-muerto cuando ya sus acreedores, despiadados y tercos, por medio de apoderados

1545 le echaron la soga al cuello; uno le traía una cuenta de plata prestada al juego; otro la de unas harinas fiadas a crecido precio; 1550 aquel, de muebles tomados a un artesano extranjero; cual de una onza, cual de cuatro, cual de veinte, cual de ciento; 
y hasta aquel documentito que aflojó sin hacer gestos cuando aquella travesura por la cual en El Comercio le dijo cierta señora, sin ambajes ni rodeos, "Ladrón, falsificador", y otros piropos como estos, se le presentó. ¿Y por quién? Esto sí parece cuento pero es la pura verdad: por el mandatario mesmo en cuya casa se hallaba como un príncipe viviendo, $y$ el que era hermano mayor del dueño del documento. Yo lo ví con estos ojos que han de salir de sus huecos, $y$ si no recuerdo mal era de pesos trescientos, a pagarse puntualmente con una onza en cada sueldo, cuyo compromiso hasta ahora anda que bebe los vientos. Mas dejemos que descanse nuestro amigo Peli-muerto y que mienta a sus anchuras sobre su estirpe y talento. con los tontos que en su vida to vieron ni conocieron: y que cuente a las muchachas su influjo con el Gobierno, sus amorosas conquistas, sus campañas y dispendios. Mientras tanto, descansar yo también un rato quiero, pues no es cosa muy sabrosa dictar versos largo tiempo.

\section{CANTO CATORCE}

Puede que algunas personas que han logrado tener flema para leer desde un principio este poema hasta la fecha, presuman que su argumento no es más que pura conseja, 
invención de mi cacumen

y de poética licencia, para entretener el tiempo y dar pábulo a la lengua. Pues señor, el que discurra de esta manera no acierta,

1605 del modo que más convenga, que lo que he dicho hasta aquí y lo que narrar me queda sobre la vida, milagros y conocidas proezas

1610 del famoso Peli-muerto, alias Sácate la Mecha, Negro Pancho, Gallinazo, Mate quiñado y Talega, es tan cierto y positivo

1615 como hay en el cielo estrellas, y tan fácil de probar como veinte y diez son treinta; porque de todo hay testigos 1620 Y todo consta de impresos, de oficios, cartas, etcétera.

Esto dicho, prosigamos nuestra historia verdadera,

1625 que he empeñado mi palabra y siendo servido Díos no seré quien falte a ella. Pagando se hallaba aún las visitas de etiqueta 1630 con que lo habían honrado los vecinos de esta tierra, cuando Pancho tuvo aviso que su idolatrada prenda,

1635 su amorosa Filomena, el blanco de sus suspiros, de sus ayes y sus penas, había llegado a Paita, conforme a su orden expresa, sin avería ninguna al parecer, por de fuera. $Y$ no vaya a creer alguno que esta terrestre sirena es la consorte que a Pancho le dió otro tiempo la Iglesia; 
nada de eso, no señor:

es una indigente huérfana,

hija de una tía suya,

a quien su fiel compañera

por caridad le había dado

en su casa cama y mesa,

para que su caro esposo

le hiciese traición con ella;

1655

bien que la pobre muchacha,

sin mundo, sin experiencia,

sin apoyo ni recursos,

tan delincuente no era

como el seductor infame,

que para mayor vergüenza

1660

la tenía ya templada

como una caja de guerra.

Apurado se vió Pancho

para ponerle vivienda

a su encantadora Filis,

1665

pues no tenía moneda

ni con qué comprar el pan

que debía mantenerla;

pero su ingenio es tan vasto

que no se para en frioleras,

1670

y al instante lo arregló

todo de aquesta manera:

hizo llevarle a hurtadillas ras

el catre, mesa y silletas

quecen el cuarto le habían puèsto

1675

para su adorno y decencia,

de cuyos muebles el dueño

el Estado no más era,

y los cuales se ha robado

pues no ha dado de ellos cuenta.

1680

Por lo que hace a la comida

puso en práctica esta treta:

adiestró a un sirviente suyo,

que era hermano de su bella,

1685

y a quien le había prohibido

que pariente le dijera,

para que se la robase

en ollitas muy pequeñas,

de la cocina del mismo

de quien subsistía a expensas,

1690 y que debajo del poncho

la llevase con cautela

al paraje en que moraba

la hermosa Dulcinea. 
Tan indecente conducta no tardó mucho en saberla la esposa del gobernante que sufría la gabela, que indignada justamente previno a su cocinera que en caso de que sobrasen provisiones en su mesa las repartiese a los pobres, mas de ninguna manera a Peli-muerto o su criado, 1705 porque era mucha insolencia que sostener torpes vicios a sus costillas quisieran. Viva se halla la señora que así procedió tan recta; 1710 vivos están los testigos de tan chistosas escenas, cuyos nombres soy capaz de decirlos, si me aprietan. $Y$ a una $y$ otros me refiero 1715 por si mi labio algo yerra. Puede ser que alguno diga que esta crítica es severa, y que a la vida priveda pertenece la ocurrencia, 1720 porque a los nietos de Adán nos gustan las hijas de Eva, etras y porque nadie está libre de que lo tiente Pateta. Pero mucho se equivocan 1725 los que de este modo piensan, pues no hay nada de privado en traer mujer de otras tierras para vivir y comer públicamente con ella, 1730 abandonando a su esposa y a dos criaturas tiernas, a quienes no dió un vestido, ni un dulce, ni una peseta, en dos años que folgó 1735 con aquella su parienta en Piura, Paita, Sullana, en Amotape y La Brea. Mas dejemos esto a un lado para hablar de otra materia 1740 que más que esta desgraciada por ahora nos interesa. 
Peli-muerto no perdía de vista nunca la idea de ser aquí Secretario

1745 - por la razón o la fuerza; así es que le declaró al que lo era cruda guerra, procurándole enemigos con falsedades groseras, y cometiendo contra él tales y tantas torpezas que no puedo recordarlas con total indiferencia. Su objeto era suplantarlo aun contra viento y marea, sin reparar en los medios por reprobados que fueran; pero nada sacó entonces, porque tuvo la entereza el Jefe de la Provincia de despreciar la caterva que contra su Secretario había alzado bandera, conservándole en justicia su amistad y consecuencia, hasta la hora en que entregó el gobierno de esta tierra, para responder en juicio de la errónea inteligencia con gue hizo cumplir ung orden de la autoridad suprema.

\section{CANTO QUINCE}

El nuevo Jefe era un hombre de prendas muy elevadas, liberal, recio, entendido, y poco amigo de farsas; con él los aduladores no andaban con muchas chanzas, y cada bicho cumplía su deber como Dios manda;

1772. - Se refiere al coronel José Noriega, subprefecto de la provincia de Piura, quien asumió accidentalmente el despacho de la gobernación en enero de 1848. Era un veterano de la independencia, y ostentaba su grado desde el 22 de diciembre de 1842. 
así es que en vano intentaron Peli-muerto y su comparsa ganarse su voluntad con halagos y amenazas, teniendo por consiguiente que tocar la retirada para emprender sus ataques por otra parte más flaca. Sabedores que debía ser restituído a su plaza el suspenso gobernante, absuelto ya de su falta, contra el pobre Secretario volvieron luego a la carga; le supusieron que había

1795 dirigido muchas cartas al Gobierno y a personas en Lima de alta importancia, para que no terminase de dicho Jefe la causa.

1800 Le supusieron también que en público lo trataba de jugador, decidioso, inepto, vicioso y mandria; que escribía por la imprenta 1805 apodando su prosapia; que le buscaba enemigos con notoria petulancia. y por último alcanzaron, con estas $y$ otras patranas, 1810 que el hombre débil y crédulo que bajamente incensaban, al tomar de nuevo el mando diese gusto a la canalla, despojando del destino 1815 bajo formas arbitrarias a un empleado que en su vida le había ofendido en nada. Sí señor; en nada digo, no porque tema la saña del ofensor, ni tampoco porque de él espere gracia, sino porque ésto es tan cierto como fué la acción villana.

1825 Y ellos cargaron la infamia. Ya, en fín, logró Peli-muerto lo que tanto ambicionaba; 
ya dirige al que gobierna, y le obliga a firmar cartas $y$ oficios en que denigra y menosprecia a sus anchas al que sólo por su empleo persigue con tanta rabia. Lo que menos dijo de él fué que era un burro en dos patas, corrompido, revoltoso, sin pundonor y sin crianza; cosas que ofendían más al que las notas firmaba que al que querían con ellas desopinar a mansalva. Ya los públicos negocios a escondidas se despachan, porque en los demás empleados no se tiene ya confianza; ya las hojas de los libros copiadores quedaron blancas; los documentos no vuelven al sitio de dó se sacan; las puertas de la oficina a toda hora están cerradas; y en fín, todo era aquel tiempo un desorden que abismaba, como lo pueden decir los empleados de que se habla, los libros y los archivos que aún no han salvado esas faltas. Mas no tan impunemente los pillos se pavoneaban; la prensa empezó a batirlos y a publicar sus marañas. $Y$ Peli-muerto, que es hombre tan pedante como maula, escribió también inepcias y diatribas sin sustancia, por las cuales se le dijo lo que un perro no aguantara, y lo que yo no podría referir en diez semanas. Pero esto en vez de enojarlo le servía de pantalla para informar al Gobierno que él era aquí su bitácora, y para acusar a otros de turba inquieta y alzada 
que en justicia se debía castigar con cuatro balas.

Por supuesto, en cada nota repetía con instancia que no habiendo Secretario, que hacía notable falta, a ninguno mejor que a él se debía dar la plaza, porque a más de su talento era fiel y de confianza;

a lo que el Gobierno siempre, - como un puto callaba - si respondía era diciendo claro necuacuan.

1890 Viendo que por este lado iba la cosa algo mala, varió Peli-muerto el rumbo en busca de la piltrafa, y ser Capitán de Puerto pensó por angas o mangas. Y para obtener el triunfo en esta nueva campaña, hizo que el Gobernador oficialmente acusara de incapaz, contrabandista, y no sé de qué otras tachas al que tenía el destino que quería echarle garra, 1905 alcanzó diesen de baja. Sin embargo, el Presidente lo dejó tocando tablas, porque esta vez como la otra no quiso ocuparlo en nada.

1910 Y en verdad que a Su Excelencia la justicia le sobraba, porque le había supuesto varias órdenes y cartas

1915 su autoridad se invocara en pro de algunas personas que en ellas se señalaban. En tal conflicto acudió a los llantos y plegarias: envió una carta al Ministro, suplicándole en sustancia que tuviesen compasión de su familia y desgracias; 
que le diesen de comer porque el hambre lo mataba; y que si así no lo hacían se daría una estocada. Y mientras allá escribía de este modo, acá en las casas propalaba que el Gobierno por fuerza lo destinaba y que no sabía qué hacer en tan graves circunstancias.

Por último, el Presidente, cediendo a súplicas tantas, y más al Gobernador, que en reserva le rogaba que sacase a Peli-muerto de esta ciudad sin tardanza, porque lo tenía ya aburrido hasta las cachas, le dió la Capitanía aunque con gran repugnancia; pero con la condición que al instante se juntara con su legítima esposa que tenía abandonada. Mientras pasaba todo esto, la prensa aquí no cesaba de combatir los abusos y hacer públicas las trampas que alaprovincial tenian onverso" en inquietud $y$ en alarma. $Y$ no encontrando razones Peli-muerto y su comparsa para acallar el clamor que así contra ellos se alzaba, una noche se robaron de la imprenta quince cajas, descerrajando las puertas en donde ellas se guardaban; pero en vano, porque entonces se siguió con más constancia en la prensa y fuera de ella zurrándoles la badana.

Peli-muerto marchó en fín a su ínsula Barataria; su mujer vino muy pronto a hacerle en ella compaña, del engaño y la falacia, 
en deplorable abandono, sin un medio y desahuciada, se fué a Lima con una hija, 1975 fruto de su suerte amarga, y en un hospital allí murió, en la propia covacha en que la madre de Pancho rindió su última jornada

1980 cuando su hijo y su marido la hora al público anunciaban. 1985 por odios eleccionarios,

Para cortar las rencillas que aquí se habían alzado, promovidas casi todas $\mathrm{y}$ en las que tomaban parte el mandón y su payaso. el Gobierno tuvo a bien trasladar al funcionario

1990 que en vez de apagar el fuego se recreaba en atizarlo.

Peli-muerto se quedó en su ínsula, sin embargo, cometiendo a su placer

1995 desbarro sobre desbarro.

Ora J contra reglamento permitía a los extraños que tocasen con sus buques en el puerto de su mando, con tal que unas cuantas onzas le obsequiasen para mangos; ora el dinero y efectos se apropiaba de los náufragos, sin piedad del infortunio y con mengua de su rango; ora infringiendo las leyes protegía el contrabando, con tal que sólo lo hiciesen los que eran sus partidarios; ora por una chalupa que compró para el Estado en treinta o cuarenta pesos la cargaba en ciento y tantos. En fín, estas y otras faltas, repetidas con escándalo, 
obligaron al Gobierno

a castigar al culpado, y sometiéndolo a juicio por un supremo mandato, lo suspendió del empleo y lo separó en el acto de aquella Capitanía que asaltó con sus amaños. Peli-muerto volvió a Piura como un loco desatado, y empezó a escribir artículos inmundos y estrafalarios contra el Administrador de Paita y contra otros cuantos a quienes llamaba autores de sus propios descalabros.

A la sazón había vuelto ce Lima aquel Secretario a quien se intentó tratar en un tiempo como esclavo, a pesar que Peli-muerto al Gobierno había mandado un pasquín en que apodaba al predicho Secretario de pícaro, demagogo, de pleitista y de zamarro. Y lo más célebre es que en su mismo suelo patrio lo llamaba hasta extranjero sólo por acriminarlo.

Al verlo ejercer de nuevo el destino tan ansiado, volvió contra él otra vez lo mismo que contra el diablo; y no se pasaba un día sin que lo acusara de algo al Jefe de la provincia, que aunque era débil y manso no se llevaba de enredos ni de chismes de malvados, y todo se lo contaba al instante al Secretario. También se había repuesto al Capitán suplantado, al que igualmente volvió a perseguir sin descanso; porque para este buen hombre, o más bien para este fatuo, 
2065

no había mayor delito que tener algún encargo que lo quisiese para él. o para otros de su bando.

Antes de marcharse a su ínsula

2070 había aquí redactado Peli-muerto dos periódicos que aun a la plebe hostigaron, y a su vuelta escribió otro que también murió temprano, no obstante que a fuer de simple y por oir llamarse sabio, andaba con los bolsillos de ejemplares atestados para darlos por las calles hasta a los negros y zambos.

$2080 \quad Y$ los más gracioso es que mientras se daba el lauro en las casas y tertulias de editor de esos embarros, 2085 con hipócrita aparato y $\sin$ vengüenza ninguna, sostenía lo contrario.

El Gobierno, convencido

2090

2095 que Peli-muerto era un zángano perjüdicial al sosiego de todo este vecindario, ordenó se fuesé a Lima nverso" sin excusa, en cualquier barco que zarpase en ese mes de Paita para el Callao; lo que no quiso efectuar, aunque cobró para el caso los haberes que tenía hasta esa fecha ganados.

2100 Entonces el Presidente no encontrando en qué ocuparlo (tales fueron las palabras de que hizo uso en su mandato) lo declaró en cesantía, 2105 mas sin dejar de llamarlo para que en la capital le ajustasen el salario. Aquí no tuvo ya límites la furia del negro Pancho

2110 que creyendo autor de esta orden al infeliz Secretario, 
le declaró guerra a muerte por todos cuatro costados. Dé palabra y por escrito disparó contra él sus rayos; lo calumnió, lo insultó a su gusto y $\sin$ reparo; buscó firmas por el pueblo para herirlo y acusarlo, y no omitió diligencia a fín de inferirle daño. En este tiempo se hallaba el Gobernador postrado del mal que lo separó para siempre de estos barrios; y Peli-muerto, que en todo se mete sin ser llamado, se acercó a la cabecera del ya moribundo anciano, y botó a los sacerdotes que allí se hallaban/rezando, diciéndoles "que al paciente fastidiaban con sus salmos", y exigió que se le diese el dinero para el gasto; y daba órdenes al médico, y regañaba a los criados; y esto hallándose presente y en su casa con el mando la consorte del enfermo, onverso" que redoblaba su llanto al ver que un entrometido así la estaba ultrajando. El Gobernador murió, y un honrado cuidadano vino de Lima a ocupar el puesto que estaba vaco. Peli-muerto escribió entonces un artículo adulándolo, y poco después su pluma lo acusó de despilfarro de las rentas nacionales; pero su nombre ocultando con el de cierto impresor que se decía agraviado en un asunto resuelto por distinto mandatario. En esta ocasión tampoco se le olvidó al negro Pancho 
el tratar de indisponer con su Jefe al Secretario, a quien profesaba un rencor tan negro como su casco.

2165 en que habita el mandatario le arrojó varios anónimos en que trataba a ese empleado como un traidor, un espía, como un bruto y un villano;

2170 y hasta hizo escribir de Lima otros así sazonados los que vió el Gobernador con el desprecio más alto, porque es un hombre de mundo

2175

2180

2185

2190

2195 $\mathrm{y}$ a intrigas tales hace asco. Estos manejos rastreros aquí sólo no pararon; anónimos más inicuos dirigía al Secretario, - en que apuraba el insulto del modo más ruin y bajo, $y$ en términos tan obscenos, tan sucios, tan desalmados, que los oídos más impuros no querrían escucharlos. La Tarántula, periódico que vió la luz invocandoe Letras el auxilio de un partido a quien nadie hacía agravio, $y$ del que era redactor nuestro impertérrito zambo, también decía dicterios entonces al Secretario y a otras personas notables que aún tienen su honor intacto, a pesar de las calumnias y los groseros sarcasmos...

2186.- Mariano Felipe Paz Soldán no menciona en su Biblioteca Peruana ningún periódico titulado La Tarántula. Y Jorge Zevallos Quiñones (en su bibliografía de La Imprenta en el Norte del Perú) lo cita basándose sólo en una referencia. Habríase publicado en 1851. 